\title{
Lack of association between vitamin D receptor gene BsmI polymorphism and breast cancer risk: an updated meta-analysis involving 23,020 subjects
}

\author{
Yingying Du $\cdot$ Lixia Hu $\cdot$ Fanliang Kong $・$ Yueyin Pan
}

Received: 21 July 2013 / Accepted: 25 September 2013 /Published online: 20 November 2013

(C) The Author(s) 2013. This article is published with open access at Springerlink.com

\begin{abstract}
The vitamin D receptor (VDR) is a crucial mediator for the cellular effects of vitamin D. A great number of studies regarding the association between $B s m I$ polymorphism in the VDR gene and breast cancer have been published. However, the results have been contradicting. Therefore, we conducted a meta-analysis to re-examine the controversy. Published literatures from PubMed, Embase, and Chinese Biomedical Literature Database (CBM) were searched (updated to July 10, 2013). The principal outcome measure was the odds ratio (OR) with $95 \%$ confidence interval (CI) for breast cancer risk associated with VDR BsmI polymorphism. With all studies involved, the meta-analysis results suggest no statistically significant association between VDR BsmI polymorphism and breast cancer risk (B vs. b, OR $=0.922,95 \% \mathrm{CI}=$ $0.836-1.018, P=0.108, I^{2}=80.0 \%$; BB vs. bb, $\mathrm{OR}=0.843$, $95 \% \mathrm{CI}=0.697-1.021, P=1.75, I^{2}=75.5 \%$; Bb vs. bb, OR= $0.930,95 \% \mathrm{CI}=0.814-1.063, P=0.31, I^{2}=73.1 \%$; $\mathrm{BB}+\mathrm{Bb}$ vs. bb, $\mathrm{OR}=0.906,95 \% \mathrm{CI}=0.787-1.043, P=1.37, I^{2}=$ $78.7 \%$; BB vs. bb+Bb, OR $=0.899,95 \% \mathrm{CI}=0.786-1.028$, $P=1.56, I^{2}=61.0 \%$ ). The results were not changed when studies were stratified by ethnicity or source of controls. This meta-analysis suggested that there were no associations between VDR BsmI polymorphism and breast cancer.
\end{abstract}

Yingying Du and Lixia Hu contributed equally to this work and should be considered as co-first authors.

Y. Du $\cdot$ Y. Pan $(\bowtie)$

Department of Oncology, The First Affiliated Hospital of Anhui Medical University, No. 218, Ji Xi Road, Hefei 230022, Anhui,

China

e-mail: yueyinpan1965@gmail.com

L. $\mathrm{Hu} \cdot \mathrm{F}$. Kong

Department of Oncology, The Second People's Hospital of Hefei, Hefei, Anhui, China
Keywords Vitamin D receptor · Polymorphism · Breast cancer $\cdot$ Meta-analysis

\section{Introduction}

Breast cancer is one of the most common cancers and the second leading cause of cancer-related deaths among women in the world [1]. Despite the frequency and severity of breast cancer, the pathogenesis and progression of breast cancer are still not fully understood. Many researchers have concluded that breast cancer is the cumulative result of multiple environmental factors and genetic alterations [2]. Risk factors for breast cancer include estrogen stimulation [3], high birth weight [4], obesity [5], and family history of breast cancer [6, 7]. In addition, genome-wide association studies provide evidence that genetic factors are important in the pathogenesis of breast cancer [8].

Data are accumulating regarding the protective role of vitamin $\mathrm{D}$ in various types of cancers [9]. In vitro studies revealed that vitamin $\mathrm{D}$ enhanced the differentiation and apoptosis of cancer cells in culture [10] including mammary glands [11]. The effects of vitamin D are mediated via the vitamin D receptor (VDR) which is expressed in most cell types, including breast tissues [12]. The VDR gene is located on chromosome 12q12-q14, and several single-nucleotide polymorphisms (SNPs) have been identified that may influence cancer risk [13]. One of the most frequently studied SNPs is the restriction fragment length polymorphism BsmI (rs1544410). The BsmI is intronic and located at the $3^{\prime}$ end of the gene. BsmI is strongly linked with a poly (A) microsatellite repeat in the $3^{\prime}$ untranslated region, which may influence VDR messenger RNA stability [14]. Over the last two decades, a number of case-control studies were conducted to investigate the association of variants in the VDR gene BsmI polymorphism and the risk of breast cancer. However, the results of these studies are controversial. Therefore, we decided to 
perform a comprehensive meta-analysis of all published studies on the association between the most studied vitamin D receptor gene $B s m I$ polymorphism and breast cancer.

\section{Materials and methods}

Publication search

We performed a comprehensive search of PubMed, Embase, and Chinese Biomedical Literature Database (CBM) to identify relevant articles on the association between the VDR BsmI polymorphism and breast cancer risk up to July 10, 2013. The search terms used were as follows: "VDR or vitamin D receptor," "BsmI or rs1544410," "cancer or tumor or carcinoma," "breast," and "polymorphism or polymorphisms." Additional literature was collected from crossreferences within both original and review articles. No language restrictions were applied. We also checked the references from retrieved articles and reviews to identify any additional relevant study.

\section{Inclusion criteria}

For inclusion, the studies must have met the following criteria: (1) assessing the VDR BsmI polymorphism and breast cancer risk, (2) applying case-control studies or nested case-control study, and (3) supplying the number of individual genotypes for the VDR BsmI polymorphism in breast cancer cases and controls, respectively. Reviews, case-only studies, or studies with overlapping data were all excluded.

\section{Data extraction}

The following information was collected from each study: the first author's name, the year of publication, sources of controls, sample size of cases and controls, genotyping method, number of breast cancer cases, controls with different genotypes, and the Hardy-Weinberg equilibrium (HWE) of controls, respectively. Different ethnicity descents were categorized as Asians, Caucasians, African-Americans, or Hispanics. Study design was stratified into hospital-based studies or population-based studies. Data were extracted independently by two investigators, and the disagreements during the data extraction were resolved by discussion among all reviewers.

\section{Quality score assessment}

The quality of the studies was also independently assessed by the same two reviewers according to the predefined scale for quality assessment. These scores were based on both

Table 1 Characteristics of case-control studies included in a meta-analysis of the relation between the BsmI polymorphism in the vitamin D receptor gene and breast cancer

\begin{tabular}{|c|c|c|c|c|c|c|c|c|c|c|c|c|c|c|}
\hline \multirow[t]{2}{*}{ ID } & \multirow[t]{2}{*}{ First author } & \multirow[t]{2}{*}{ Year } & \multirow[t]{2}{*}{ Ethnicity } & \multirow{2}{*}{$\begin{array}{l}\text { Source of } \\
\text { controls }^{\mathrm{a}}\end{array}$} & \multirow[t]{2}{*}{ Cases/controls } & \multirow{2}{*}{$\begin{array}{l}\text { Genotyping } \\
\text { method }\end{array}$} & \multicolumn{3}{|c|}{ Case } & \multicolumn{3}{|c|}{ Control } & \multirow[t]{2}{*}{ HWE } & \multirow{2}{*}{$\begin{array}{l}\text { Quality } \\
\text { score }\end{array}$} \\
\hline & & & & & & & $\mathrm{bb}$ & $\mathrm{Bb}$ & BB & $\mathrm{bb}$ & $\mathrm{Bb}$ & BB & & \\
\hline 1 & Ingles [20] & 2000 & Caucasian & Population & $143 / 300$ & TaqMan & 61 & 68 & 14 & 169 & 112 & 19 & 0.939 & 13 \\
\hline 2 & Bretherton-Watt [21] & 2001 & Caucasian & Hospital & $181 / 241$ & QIAamp & 78 & 84 & 19 & 39 & 133 & 69 & 0.06 & 10 \\
\hline 3 & Hou $[22]$ & 2002 & Asian & Hospital & $34 / 169$ & PCR-RFLP & 27 & 6 & 1 & 153 & 16 & 0 & 0.518 & 10 \\
\hline 4 & Buyru [23] & 2003 & Caucasian & Hospital & $78 / 27$ & PCR-RFLP & 18 & 45 & 15 & 5 & 17 & 5 & 0.178 & 10 \\
\hline 5 & Guy [24] & 2004 & Caucasian & Hospital & $398 / 427$ & PCR-RFLP & 173 & 173 & 52 & 139 & 215 & 73 & 0.513 & 9 \\
\hline 6 & Chen [25] & 2005 & Caucasian & Population & $1,180 / 1,547$ & TaqMan & 431 & 586 & 163 & 565 & 737 & 245 & 0.857 & 11 \\
\hline 7 & Lowe [26] & 2005 & Caucasian & Population & $179 / 179$ & PCR-RFLP & 84 & 70 & 25 & 52 & 99 & 28 & 0.091 & 10 \\
\hline 8 & McCullough [27] & 2007 & Caucasian & Population & $472 / 460$ & TaqMan & 151 & 237 & 84 & 170 & 216 & 74 & 0.698 & 14 \\
\hline 9 & Sinottte2 [28] & 2008 & Caucasian & Population & $617 / 956$ & TaqMan & 237 & 300 & 80 & 355 & 461 & 140 & 0.625 & 15 \\
\hline 10 & McKay1 [29] & 2009 & Caucasian & Mixed & $1,596 / 2,620$ & TaqMan & 573 & 767 & 256 & 951 & 1,219 & 450 & 0.08 & 9 \\
\hline 11 & McKay2 [29] & 2009 & Caucasian & Population & $1,065 / 1,097$ & TaqMan & 405 & 468 & 192 & 407 & 533 & 157 & 0.408 & 13 \\
\hline 12 & McKay3 [29] & 2009 & Caucasian & Population & $604 / 604$ & TaqMan & 201 & 303 & 100 & 200 & 298 & 106 & 0.782 & 13 \\
\hline 13 & Anderson [30] & 2011 & Caucasian & Population & $1,553 / 1,629$ & PCR-RFLP & 538 & 746 & 269 & 592 & 749 & 288 & 0.057 & 15 \\
\hline 14 & Rollison [31] & 2011 & Mixed & Population & $1,740 / 2,047$ & PCR-RFLP & 247 & 809 & 684 & 278 & 905 & 864 & 0.095 & 12 \\
\hline 15 & Shahbazi [32] & 2013 & Asian & Population & $140 / 156$ & QIAamp & 51 & 73 & 16 & 48 & 72 & 36 & 0.372 & 12 \\
\hline 16 & Mishra1 [33] & 2013 & African-American & Hospital & $115 / 73$ & PCR-RFLP & 66 & 40 & 9 & 34 & 31 & 8 & 0.816 & 9 \\
\hline 17 & Mishra2 [33] & 2013 & Hispanic & Hospital & $117 / 276$ & PCR-RFLP & 57 & 50 & 10 & 148 & 110 & 18 & 0.686 & 10 \\
\hline
\end{tabular}

HWE Hardy-Weinberg equilibrium, PCR-RFLP polymerase chain reaction restriction fragment length polymorphism

${ }^{a}$ Hospital: hospital-based case-control study; population: population-based case-control study 
traditional epidemiological considerations and cancer genetic issues. Any disagreement was resolved by discussion between the two reviewers. Total scores ranged from 0 (worst) to 15 (best). Reports scoring $<10$ were classified as "low quality" and those $\geq 10$ as "high quality."

\section{Statistical analysis}

For each case-control study, the HWE of genotypes in the control group was assessed by using the chi-square test in the control groups [15]. The pooled odds ratio (OR) and corresponding $95 \%$ confidence interval (CI) were calculated to assess the strength of the association between VDR BsmI polymorphism and breast cancer risk. To estimate associations with breast cancer risk, five genetic models were selected, including the allelic (B vs. b), homozygous (BB vs. bb), additive ( $\mathrm{Bb}$ vs. $\mathrm{bb})$, recessive ( $\mathrm{BB}$ vs. $\mathrm{Bb}+\mathrm{bb})$, and dominant $(\mathrm{BB}+\mathrm{Bb}$ vs. bb) models. Subgroup analyses based on ethnicity and source of controls were also performed.

Heterogeneity among studies was assessed by the chisquare test-based $Q$ statistic and $I^{2}$ statistic [16]. A significant $Q$ statistic $(P<0.10)$ indicated heterogeneity across studies. In case a significant heterogeneity was detected, the random effects model (the DerSimonian Laird method) [16] was applied; otherwise, the fixed effects model (Mantel-Haenszel method) [17] was chosen.

The possibility of publication bias was assessed by using a funnel plot [18] and Egger's linear regression test [19]. An asymmetric funnel plot suggests a possible publication bias. Then, the funnel plot asymmetry was assessed by Egger's linear regression test, and the significance of the intercept was determined by the $t$ test suggested by Egger $(P<0.05$ indicates significant publication bias).

Analyses were performed using the software Stata version 12.0 (Stata Corporation, College Station, TX, USA). A $P$ value of less than 0.05 was considered statistically significant.

\section{Results}

Characteristics of included studies

A total of 17 eligible studies met the inclusion criteria [20-33]. All of the included studies were case-control or cohort
Table 2 Summary ORs and $95 \%$ CI for various contrasts in VDR BsmI polymorphism

$O R$ odds ratio, $C I$ confidence interval, $R$ random effects model

\begin{tabular}{|c|c|c|c|c|c|c|c|}
\hline \multirow[t]{2}{*}{ Total studies } & \multicolumn{3}{|l|}{ Test of association } & \multicolumn{3}{|c|}{ Test of heterogeneity } & \multirow[t]{2}{*}{ Mode } \\
\hline & OR $(95 \% \mathrm{CI})$ & $Z$ & $P$ & $\chi^{2}$ & $P$ & $I^{2}$ & \\
\hline \multicolumn{8}{|l|}{ All studies (17) } \\
\hline B vs. b & $0.922(0.836-1.018)$ & 1.61 & 0.108 & 80.19 & 0.000 & 80.0 & $\mathrm{R}$ \\
\hline BB vs. bb & $0.843(0.697-1.021)$ & 1.75 & 0.080 & 65.29 & 0.000 & 75.5 & $\mathrm{R}$ \\
\hline $\mathrm{Bb}$ vs. bb & $0.930(0.814-1.063)$ & 0.31 & 0.759 & 59.41 & 0.000 & 73.1 & $\mathrm{R}$ \\
\hline $\mathrm{BB}+\mathrm{Bb}$ vs. $\mathrm{bb}$ & $0.906(0.787-1.043)$ & 1.37 & 0.170 & 75.22 & 0.000 & 78.7 & $\mathrm{R}$ \\
\hline $\mathrm{BB}$ vs. $\mathrm{bb}+\mathrm{Bb}$ & $0.899(0.786-1.028)$ & 1.56 & 0.119 & 41.93 & 0.000 & 61.0 & $\mathrm{R}$ \\
\hline \multicolumn{8}{|c|}{ Hospital-based (6) } \\
\hline B vs. b & $0.838(0.559-1.255)$ & 0.86 & 0.390 & 34.63 & 0.000 & 85.6 & $\mathrm{R}$ \\
\hline BB vs. bb & $0.644(0.275-1.509)$ & 1.01 & 0.311 & 27.52 & 0.000 & 81.8 & $\mathrm{R}$ \\
\hline Bb vs. bb & $0.737(0.462-1.175)$ & 1.28 & 0.200 & 20.75 & 0.001 & 61.8 & $\mathrm{R}$ \\
\hline $\mathrm{BB}+\mathrm{Bb}$ vs. $\mathrm{bb}$ & $0.736(0.426-1.271)$ & 1.10 & 0.271 & 31.89 & 0.000 & 84.3 & $\mathrm{R}$ \\
\hline $\mathrm{BB}$ vs. $\mathrm{bb}+\mathrm{Bb}$ & $0.757(0.419-1.366)$ & 0.92 & 0.356 & 15.92 & 0.007 & 68.6 & $\mathrm{R}$ \\
\hline \multicolumn{8}{|c|}{ Population-based (12) } \\
\hline B vs. b & $0.838(0.559-1.255)$ & 0.45 & 0.655 & 25.38 & 0.003 & 25.38 & $\mathrm{R}$ \\
\hline BB vs. bb & $0.959(0.823-1.118)$ & 0.53 & 0.595 & 19.98 & 0.018 & 55.0 & $\mathrm{R}$ \\
\hline $\mathrm{Bb}$ vs. bb & $1.007(0.889-1.141)$ & 0.11 & 0.915 & 23.53 & 0.005 & 61.8 & $\mathrm{R}$ \\
\hline $\mathrm{BB}+\mathrm{Bb}$ vs. $\mathrm{bb}$ & $0.992(0.880-1.120)$ & 0.12 & 0.902 & 24.51 & 0.004 & 63.3 & $\mathrm{R}$ \\
\hline $\mathrm{BB}$ vs. $\mathrm{bb}+\mathrm{Bb}$ & $0.957(0.840-1.089)$ & 0.67 & 0.504 & 19.22 & 0.023 & 53.2 & $\mathrm{R}$ \\
\hline \multicolumn{8}{|l|}{ Caucasian (12) } \\
\hline B vs. b & $0.918(0.817-1.031)$ & 1.44 & 0.150 & 67.73 & 0.000 & 83.8 & $\mathrm{R}$ \\
\hline BB vs. bb & $0.845(0.675-1.058)$ & 1.47 & 0.142 & 55.38 & 0.000 & 80.1 & $\mathrm{R}$ \\
\hline $\mathrm{Bb}$ vs. bb & $0.902(0.767-1.060)$ & 1.26 & 0.209 & 55.01 & 0.000 & 80.0 & $\mathrm{R}$ \\
\hline $\mathrm{BB}+\mathrm{Bb}$ vs. $\mathrm{bb}$ & $0.883(0.745-1.046)$ & 1.44 & 0.150 & 67.69 & 0.000 & 83.8 & $\mathrm{R}$ \\
\hline $\mathrm{BB}$ vs. $\mathrm{bb}+\mathrm{Bb}$ & $0.915(0.783-1.069)$ & 1.12 & 0.261 & 31.78 & 0.001 & 65.4 & $\mathrm{R}$ \\
\hline
\end{tabular}


studies. In total, 10,212 cases and 12,808 controls were included in the pooled analyses. Of the 17 studies for polymorphisms, there were 12 with Caucasian ethnicity, 2 with Asian ethnicity, 1 with Hispanic ethnicity, 1 with mixed ethnicity, and 1 with American-African populations. The characteristics of the selected studies are summarized in Table 1.

\section{Meta-analysis}

The results on the association between VDR BsmI polymorphism and susceptibility to breast cancer are shown in Table 2 . Meta-analysis of the 17 studies suggested that there was no association between VDR BsmI polymorphism and susceptibility to breast cancer (B vs. b, OR $=0.922,95 \% \mathrm{CI}=0.836$ $1.018, P=0.108, I^{2}=80.0 \%$; BB vs. bb, $\mathrm{OR}=0.843,95 \%$ $\mathrm{CI}=0.697-1.021, P=1.75, I^{2}=75.5 \%$; Bb vs. bb, OR= $0.930,95 \% \mathrm{CI}=0.814-1.063, P=0.31, I^{2}=73.1 \%$; BB+ $\mathrm{Bb}$ vs. bb, $\mathrm{OR}=0.906,95 \% \mathrm{CI}=0.787-1.043, P=1.37$, $I^{2}=78.7 \%$; BB vs. bb $+\mathrm{Bb}, \mathrm{OR}=0.899,95 \% \mathrm{CI}=0.786-$ $1.028, P=1.56, I^{2}=61.0 \%$ ) (Table 2, Figs. 1 and 2). When stratifying for source of controls and for ethnicity, no significant association between BsmI polymorphism and breast cancer risk was observed.
Publication bias

Funnel plot and Egger's test were performed to assess the publication bias. The shape of the funnel plot did not reveal obvious evidence of asymmetry (Fig. 3), and Egger's test provided statistical evidence of funnel plot symmetry $(P>0.05$, Table 3$)$. Therefore, the results above did not suggest any evidence of publication bias in the meta-analysis.

\section{Discussion}

As with other malignancies, the pathogenesis of breast cancer involves environmental factors, molecular signaling pathways, and host genetic factors. In order to provide the most comprehensive and reliable conclusion, we performed the present meta-analysis of 17 independent case-control studies, including 10,212 cases and 12,808 controls. We explored the association between BsmI polymorphism in the VDR gene region and breast cancer risk. The results of our meta-analysis do not provide evidence for an association between the VDR BsmI polymorphism and

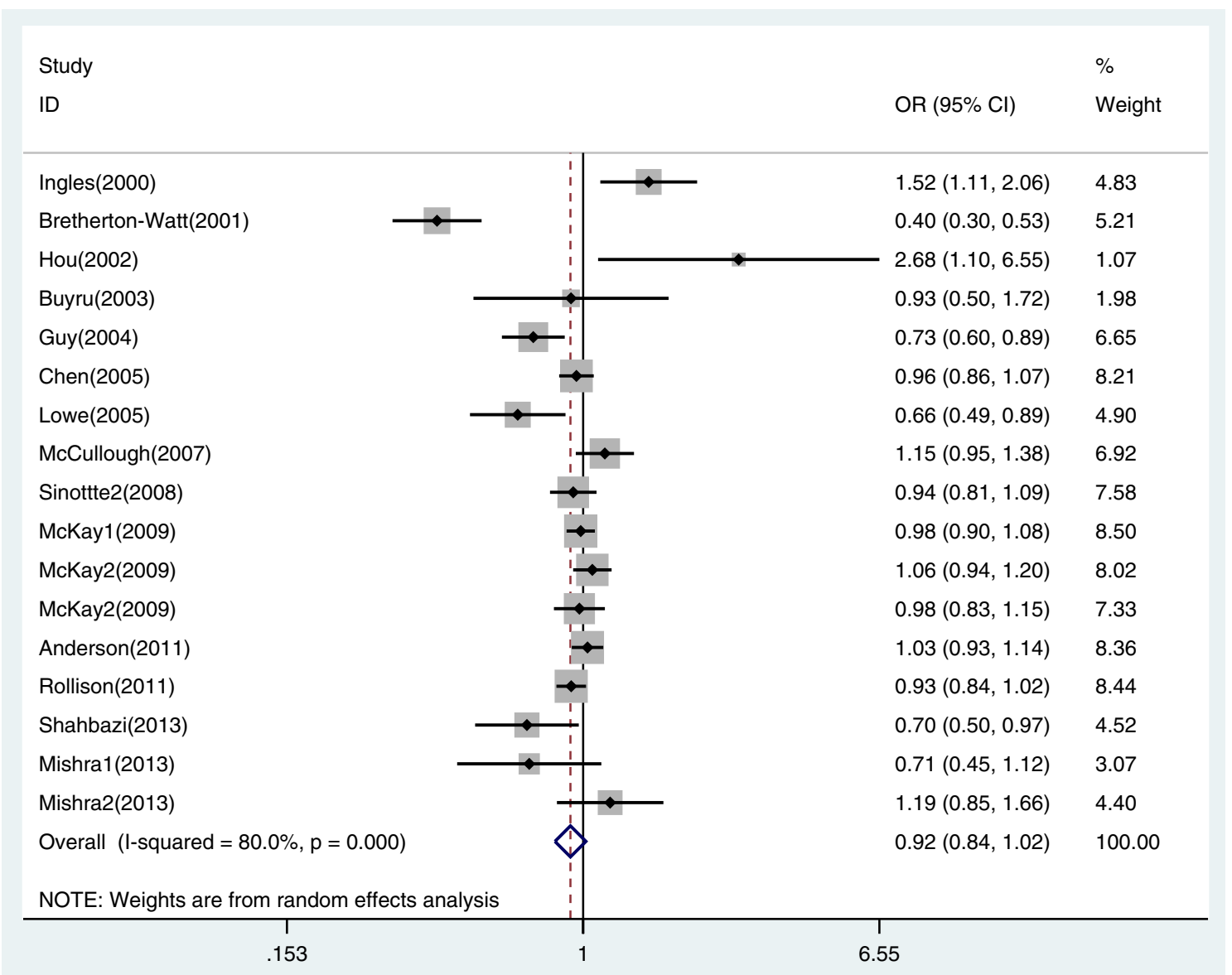

Fig. 1 Overall meta-analysis for VDR BsmI polymorphism (B vs.b) and breast cancer 


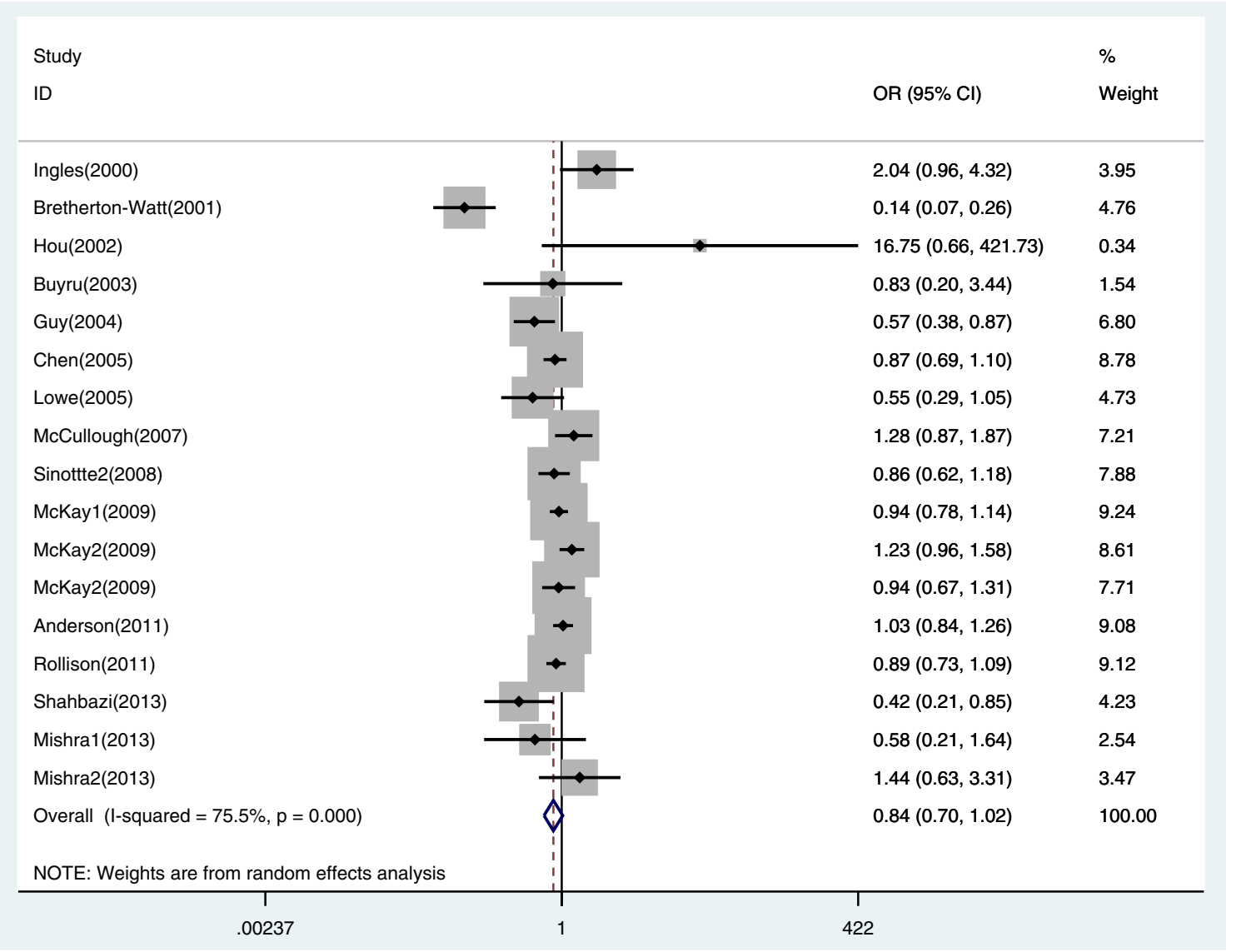

Fig. 2 Overall meta-analysis for VDR BsmI polymorphism (BB vs. bb) and breast cancer

the risk of breast cancer. It is consistent with the result of a previous meta-analysis, which was conducted by Tang et al. in 2009 [34]. However, we included 10,212 cases and 12,808 controls from 17 studies in the present meta-

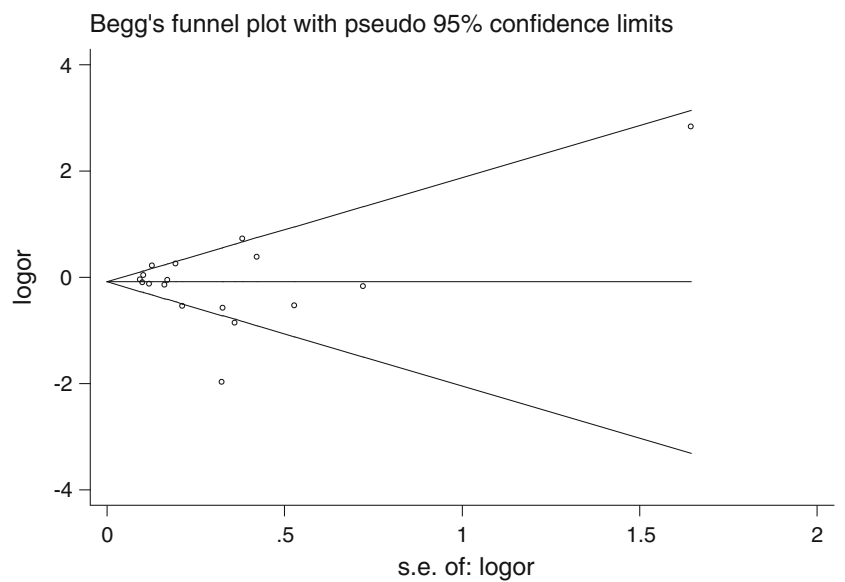

Fig. 3 Begg's funnel plots to examine publication bias for reported comparisons of VDR BsmI polymorphism (BB vs. bb). Plots are shown with pseudo $95 \%$ confidence limits. S.E. standard error. Each point represents a separate study for the indicated association analysis. Hence, a more stringent and comprehensive result has been obtained.

When stratifying for ethnicity, this present meta-analysis failed to identify the association between VDR BsmI polymorphism and susceptibility to breast cancer in Caucasians. However, there were only two from Asians, one from AfricanAmericans, and one from Hispanics, and we were unable to get a precise estimation on the association between VDR $B s m I$ polymorphism and susceptibility to breast cancer in Asians, African-Americans, and Hispanics. Therefore, future studies on Asians, African-Americans, or Hispanics are needed to further assess the above association.

Some limitations of our study should be acknowledged. First, in the subgroup analyses, the number of Asians,

Table 3 Tests for publication bias (Egger's test) in overall population

\begin{tabular}{lll}
\hline Polymorphism & Comparison & Egger's test $(P)$ \\
\hline BsmI & B vs. b & 0.491 \\
& BB vs. bb & 0.441 \\
& Bb vs. bb & 0.272 \\
& BB + Bb vs. bb & 0.289 \\
& BB vs. bb $+\mathrm{Bb}$ & 0.838 \\
\hline
\end{tabular}


African-Americans, and Hispanics was relatively small. In order to have enough statistical power to explore real association, it is necessary to collect more samples from Asians, African-Americans, and Hispanics. Second, significant heterogeneity was observed in overall comparisons and also subgroup analyses. Third, meta-analysis is just a statistical test that is subject to the methodological limitations.

Although some limitations were listed previously, there were also some advantages in our meta-analysis. First, all studies are in Hardy-Weinberg equilibrium, which indicated that the samples could better represent the expected distribution of the genotypes. Second, studies included in our metaanalysis were satisfactory and definitely met our inclusion criteria. Third, publication bias was not detected in the present study, indicating that our findings seemed not to be due to biased publications.

In summary, this meta-analysis suggests that there is no association between VDR BsmI polymorphism and susceptibility to breast cancer in Caucasians. Future studies from Asians, African-Americans, or Hispanics are needed to further assess the above association.

Acknowledgment This work was supported by a grant from Anhui Provincial Science and Technology Agency Foundation of China (no. KJ2012A157).

\section{Conflict of interest None}

Open Access This article is distributed under the terms of the Creative Commons Attribution License which permits any use, distribution, and reproduction in any medium, provided the original author(s) and the source are credited.

\section{References}

1. Smigal C, Jemal A, Ward E, Cokkinides V, Smith R, Howe HL, et al. Trends in breast cancer by race and ethnicity: update 2006. CA Cancer J Clin. 2006;56(3):168-83.

2. Lichtenstein P, Holm NV, Verkasalo PK, Iliadou A, Kaprio J, Koskenvuo M, et al. Environmental and heritable factors in the causation of cancer-analyses of cohorts of twins from Sweden, Denmark, and Finland. N Engl J Med. 2000;343(2):78-85. doi:10. 1056/NEJM200007133430201.

3. Cheung KL. Endocrine therapy for breast cancer: an overview. Breast. 2007;16(4):327-43. doi:10.1016/j.breast.2007.03.004.

4. Silva Idos S, De Stavola B, McCormack V. Birth size and breast cancer risk: re-analysis of individual participant data from 32 studies. PLoS Med. 2008;5(9):e193. doi:10.1371/journal.pmed.0050193.

5. Zaman K, Bodmer A, Pralong F, Castiglione-Gertsch M. Breast cancer and obesity, a dangerous relation. Rev Med Suisse. 2012;8(342):1101-4.

6. Berclaz G, Li S, Price KN, Coates AS, Castiglione-Gertsch M, Rudenstam CM, et al. Body mass index as a prognostic feature in operable breast cancer: the International Breast Cancer Study Group experience. Ann Oncol. 2004;15(6):875-84.
7. Hankinson SE. Circulating levels of sex steroids and prolactin in premenopausal women and risk of breast cancer. Adv Exp Med Biol. 2008;617:161-9. doi:10.1007/978-0-387-69080-3 15.

8. Wacholder S, Hartge P, Prentice R, Garcia-Closas M, Feigelson HS, Diver WR, et al. Performance of common genetic variants in breastcancer risk models. N Engl J Med. 2010;362(11):986-93. doi:10. 1056/NEJMoa0907727.

9. Krishnan AV, Swami S, Feldman D. Vitamin D and breast cancer: inhibition of estrogen synthesis and signaling. J Steroid Biochem Mol Biol. 2010;121(1-2):343-8. doi:10.1016/j.jsbmb.2010.02.009.

10. James SY, Williams MA, Kelsey SM, Newland AC, Colston $\mathrm{KW}$. The role of vitamin $\mathrm{D}$ derivatives and retinoids in the differentiation of human leukaemia cells. Biochem Pharmacol. 1997;54(5):625-34.

11. Eisman JA, Macintyre I, Martin TJ, Frampton RJ, King RJ. Normal and malignant breast tissue is a target organ for 1,25- $(0 \mathrm{H}) 2$ vitamin D3. Clin Endocrinol (Oxf). 1980;13(3):267-72.

12. Townsend K, Banwell CM, Guy M, Colston KW, Mansi JL, Stewart PM, et al. Autocrine metabolism of vitamin D in normal and malignant breast tissue. Clin Cancer Res. 2005;11(9):3579-86. doi:10. 1158/1078-0432.CCR-04-2359.

13. Raimondi S, Johansson H, Maisonneuve P, Gandini S. Review and meta-analysis on vitamin $\mathrm{D}$ receptor polymorphisms and cancer risk. Carcinogenesis. 2009;30(7):1170-80. doi:10.1093/ carcin/bgp103.

14. Uitterlinden AG, Fang Y, Van Meurs JB, Pols HA, Van Leeuwen JP. Genetics and biology of vitamin D receptor polymorphisms. Gene. 2004;338(2):143-56. doi:10.1016/j.gene.2004.05.014.

15. Haber M. Exact significance levels of goodness-of-fit tests for the Hardy-Weinberg equilibrium. Hum Hered. 1981;31(3):161-6.

16. DerSimonian R, Laird N. Meta-analysis in clinical trials. Control Clin Trials. 1986;7(3):177-88.

17. Mantel N, Haenszel W. Statistical aspects of the analysis of data from retrospective studies of disease. J Natl Cancer Inst. 1959;22(4):719 48.

18. Begg CB, Mazumdar M. Operating characteristics of a rank correlation test for publication bias. Biometrics. 1994;50(4):1088-101.

19. Egger M, Davey Smith G, Schneider M, Minder C. Bias in metaanalysis detected by a simple, graphical test. BMJ. 1997;315(7109): 629-34.

20. Ingles SA, Garcia DG, Wang W, Nieters A, Henderson BE, Kolonel $\mathrm{LN}$, et al. Vitamin D receptor genotype and breast cancer in Latinas (United States). Cancer Causes Control. 2000;11(1):25-30.

21. Bretherton-Watt D, Given-Wilson R, Mansi JL, Thomas V, Carter N, Colston KW. Vitamin D receptor gene polymorphisms are associated with breast cancer risk in a UK Caucasian population. Br J Cancer. 2001;85(2):171-5. doi:10.1054/bjoc.2001.1864.

22. Hou MF, Tien YC, Lin GT, Chen CJ, Liu CS, Lin SY, et al. Association of vitamin D receptor gene polymorphism with sporadic breast cancer in Taiwanese patients. Breast Cancer Res Treat. 2002;74(1):1-7.

23. Buyru N, Tezol A, Yosunkaya-Fenerci E, Dalay N. Vitamin D receptor gene polymorphisms in breast cancer. Exp Mol Med. 2003;35(6):550-5. doi:10.1038/emm.2003.72.

24. Guy M, Lowe LC, Bretherton-Watt D, Mansi JL, Peckitt C, Bliss J, et al. Vitamin D receptor gene polymorphisms and breast cancer risk. Clin Cancer Res. 2004;10(16):5472-81. doi:10.1158/1078-0432. CCR-04-0206.

25. Chen WY, Bertone-Johnson ER, Hunter DJ, Willett WC, Hankinson SE. Associations between polymorphisms in the vitamin D receptor and breast cancer risk. Cancer Epidemiol Biomarkers Prev. 2005;14(10):2335-9. doi:10.1158/1055-9965.EPI-05-0283.

26. Lowe LC, Guy M, Mansi JL, Peckitt C, Bliss J, Wilson RG, et al. Plasma 25-hydroxy vitamin D concentrations, vitamin D receptor genotype and breast cancer risk in a UK Caucasian population. Eur J Cancer. 2005;41(8):1164-9. doi:10.1016/j.ejca.2005.01.017. 
27. McCullough ML, Stevens VL, Diver WR, Feigelson HS, Rodriguez C, Bostick RM, et al. Vitamin D pathway gene polymorphisms, diet, and risk of postmenopausal breast cancer: a nested case-control study. Breast Cancer Res. 2007;9(1):R9. doi:10.1186/bcr1642.

28. Sinotte M, Rousseau F, Ayotte P, Dewailly E, Diorio C, Giguere Y, et al. Vitamin D receptor polymorphisms (FokI, BsmI) and breast cancer risk: association replication in two case-control studies within French Canadian population. Endocr Relat Cancer. 2008;15(4):97583. doi:10.1677/ERC-08-0056.

29. McKay JD, McCullough ML, Ziegler RG, Kraft P, Saltzman BS, Riboli E, et al. Vitamin D receptor polymorphisms and breast cancer risk: results from the National Cancer Institute Breast and Prostate Cancer Cohort Consortium. Cancer Epidemiol Biomarkers Prev. 2009;18(1):297-305. doi:10.1158/1055-9965. EPI-08-0539.

30. Anderson LN, Cotterchio M, Cole DE, Knight JA. Vitamin D-related genetic variants, interactions with vitamin $\mathrm{D}$ exposure, and breast cancer risk among Caucasian women in Ontario. Cancer Epidemiol
Biomarkers Prev. 2011;20(8):1708-17. doi:10.1158/1055-9965.EPI11-0300.

31. Rollison DE, Cole AL, Tung KH, Slattery ML, Baumgartner KB, Byers T, et al. Vitamin D intake, vitamin D receptor polymorphisms, and breast cancer risk among women living in the southwestern U.S. Breast Cancer Res Treat. 2012;132(2):683-91.

32. Shahbazi S, Alavi S, Majidzadeh AK, Ghaffarpour M, Soleimani A, Mahdian R. BsmI but not FokI polymorphism of VDR gene is contributed in breast cancer. Med Oncol. 2013;30(1):393. doi:10. 1007/s12032-012-0393-7.

33. Mishra DK, Wu Y, Sarkissyan M, Sarkissyan S, Chen Z, Shang X, et al. Vitamin D receptor gene polymorphisms and prognosis of breast cancer among African-American and Hispanic women. PLoS One. 2013;8(3):e57967. doi:10.1371/journal.pone.0057967.

34. Tang C, Chen N, Wu M, Yuan H, Du Y. Fok1 polymorphism of vitamin D receptor gene contributes to breast cancer susceptibility: a meta-analysis. Breast Cancer Res Treat. 2009;117(2):391-9. doi:10. 1007/s10549-008-0262-4. 